\title{
CONTROLE DO ESCURECIMENTO INTERNO DE AMEIXAS DURANTE O ARMAZENAMENTO PELO MANEJO DO PONTO DE COLHEITA E DO ETILENO ${ }^{1}$
}

\author{
LUIZ CARLOS ARGENTA ${ }^{2}$, CASSANDRO VIDAL TALAMINI DO AMARANTE ${ }^{3}$, \\ DAISUKE SHIRAYAMA ${ }^{4}$, ANDREIA MARIA TOMAZINI SCOLARO ${ }^{5}$, RICARDO ANTONIO AYUB
}

RESUMO - Este trabalho teve por objetivos avaliar os efeitos do estádio de maturação na colheita e do tratamento com 1-metilciclopropeno (1-MCP) sobre o escurecimento de polpa e o amadurecimento, durante o armazenamento refrigerado de ameixas 'Laetitia'. Os frutos foram colhidos em dois estádios de maturação, em pomares comerciais localizados nos municípios de Lages (em 2006 e 2008) e São Joaquim (em 2008): $20-45 \%$ da superfície vermelha (maturação 1) e 46-80\% da superfície vermelha (maturação 2). Os frutos foram armazenados em atmosfera do ar a $0,5^{\circ} \mathrm{C}^{\circ} \mathrm{C}$ e $90-95 \%$ de umidade relativa, 36 h após a colheita, tratados depois de quatro dias com zero (testemunha) ou $0,5 \mu \mathrm{L} . \mathrm{L}^{-1}$ de $1-\mathrm{MCP}$, e então mantidos sob refrigeração por até 73 dias. Os frutos foram analisados na colheita, periodicamente após a armazenagem refrigerada e após 3 dias a $22^{\circ} \mathrm{C}$. No município de Lages, frutos colhidos no estádio de maturação 1 apresentaram firmeza da polpa de 2,5 e 2,3 libras maior que frutos colhidos no estádio de maturação 2, em 2006 e 2008, respectivamente. No município de São Joaquim, frutos colhidos no estádio de maturação 1 apresentaram firmeza da polpa 1,3 libra maior que frutos colhidos no estádio de maturação 2. A colheita dos frutos em estádio mais avançado de maturação e o tratamento com 1-MCP retardaram a manifestação de escurecimento de polpa durante o armazenamento refrigerado, independentemente do município e do ano. De forma geral, em frutos colhidos no estádio de maturação 2 e tratados com 1-MCP, o aumento no período de armazenamento refrigerado, sem ocorrência do distúrbio durante os três dias de prateleira, foi $\geq 20$ dias, em relação a frutos colhidos no estádio de maturação 1 e não tratados com 1-MCP. Adicionalmente, o 1-MCP reduziu a perda de firmeza da polpa dos frutos durante o armazenamento refrigerado.

Termos de indexação: Prunus salicina, dano por frio, amadurecimento, 1-metilciclopropeno.

\section{PREVENTION OF FLESH BROWNING AND DELAYING OF FLESH FIRMNESS DURING COLD STORAGE IN 'LAETITIA' PLUMS BY MANAGEMENT OF FRUIT MATURITY AT HARVEST AND ETHYLENE USE}

ABSTRACT - This research was carried out to assess the effects of fruit maturity at harvest and its treatment with 1-methylcyclopropene (1-MCP) on flesh browning (chilling injury) and ripening during cold storage of 'Laetitia' plums. Fruits were harvested at two maturity stages in commercial orchards located in Lages (in 2006 and 2008) and São Joaquim (in 2008): with 20-45\% (maturity 1) and 46-80\% (maturity 2) of surface with red coloration. Fruit were cold stored in air, at $0.5^{\circ} \mathrm{C} \pm 0.5^{\circ} \mathrm{C}$ and $90-95 \% \mathrm{RH}$, within $36 \mathrm{~h}$ after harvest, treated four days latter with zero (control) or $0.5 \mu \mathrm{L} . \mathrm{L}^{-1}$ of $1-\mathrm{MCP}$, and then kept under refrigeration for up to 73 days. Fruit were assessed at harvest, periodically during cold storage and after three days of shelf life (at $22 \pm 4^{\circ} \mathrm{C}$ ) in terms of flesh firmness, titratable acidity (TA), soluble solids content (SSC) and incidence of shrinkage, flesh browning and decay. In Lages, fruit harvested at the maturity stage 1 had flesh firmness values of 2.5 to $2.3 \mathrm{lb}$ higher than fruit harvested at the maturity stage 2, in 2006 and 2008 , respectively. In São Joaquim, fruit harvested at the maturity stage 1 had flesh firmness value $1.3 \mathrm{lb}$ higher than fruit harvested at the maturity stage 2 . The fruit harvested at an advanced maturity (maturity 2 ) and the treatment with 1-MCP delayed the expression of flesh browning during cold storage, regardless of orchard location and year. In general, for fruit harvested at maturity stage 2 and treated with 1-MCP, the increase of cold storage period without the occurrence of flesh browning, assessed after three days of shelf life, was $\geq 20$ days, in comparison to fruit harvested at maturity stage 1 and non-treated with 1-MCP. Additionally, 1 -MCP delayed the loss of flesh firmness, but it did not substantially improve the preservation of TA and SSC of the fruit during cold storage.

Index terms: Prunus salicina, chilling injury, ripening, 1-methylcyclopropene.

\footnotetext{
'(Trabalho 085-10). Recebido em: 26-03-2010. Aceito para publicação em 22-12-2010.

${ }^{2}$ Dr., Pesquisador da Epagri, Estação Experimental de Caçador. C.P. 591, Caçador-SC. E-mail: argenta@epagri.sc.gov.br

${ }^{3} \mathrm{Ph} . D$., Bolsista de Produtividade em Pesquisa do CNPq. Prof. do Depto. de Agronomia, Centro de Ciências Agroveterinárias (CAV), UDESC. Lages-SC. E-mail: amarante@cav.udesc.br

${ }^{4}$ Eng Agr, Sanjo, Cooperativa Agrícola São Joaquim, Irineu Bornhausen, 677, 88.600-000, São Joaquim-SC. E-mail: dshirayama@gmail.com ${ }^{5}$ Eng. Agr. Bolsista do CNPq, EPAGRI, Estação Experimental de Caçador. 89500-000, Caçador-SC. E-mail: andreiascolaro@hotmail.com ${ }^{6}$ Ph.D., Prof. do Depto de Fitotecnia, UEPG. Av. Gal. Carlos Cavalcante, 4748, Ponta Grossa-PR. Email: rayub@uepg.br
} 


\section{INTRODUÇÃO}

A cultivar de ameixa 'Laetitia' é a mais plantada nos Estados de Santa Catarina e Rio Grande dos Sul, devido à boa produtividade e qualidade dos frutos, e à baixa suscetibilidade a doenças (especialmente Xantomonas) (DUCROQUET et al., 2001). O aumento da produção desta cultivar tem resultado no prolongamento do período de comercialização dos frutos, com o consequente aumento das perdas por deterioração após a colheita. Ressalta-se que ameixas 'Laetitia' exibem padrões climatéricos de respiração e produção de etileno, fatores associados às rápidas mudanças da textura após a colheita (ARGENTA et al., 2003).

Os frutos de caroço (ameixa, pêssego e nectariana) apresentam alta perecibilidade, devido à rápida maturação e senescência, e elevada ocorrência de doenças pós-colheita (KADER; MITCHELL, 1989). A armazenagem refrigerada é a principal tecnologia para a conservação da qualidade e o prolongamento da vida pós-colheita em frutos de caroço, pois reduz a respiração, a produção de etileno, a perda de água e o desenvolvimento de podridões, e retarda o amadurecimento (KADER; MITCHELL, 1989). No entanto, a maioria das cultivares de frutos de caroço de clima temperado (Prunus spp.) é suscetível a danos por frio (MITCHELL; KADER, 1989; CRISOSTO et al., 1999). O desenvolvimento de dano por frio aumenta com o tempo de armazenamento refrigerado, e normalmente é mais rápido e severo quando frutos de cultivares suscetíveis de pêssego, nectarinas e ameixas são armazenados em temperaturas de $2,2^{\circ} \mathrm{C}$ a 7,8 $8^{\circ} \mathrm{C}$ (MITCHELL; KADER, 1989; LURIE; CRISOSTO, 2005). Cultivares tardias de pêssego e nectarina são normalmente mais suscetíveis ao dano por frio que cultivares precoces, embora essa relação não seja evidente para ameixas (MITCHELL; KADER, 1989; CRISOSTO et al., 1999). Os efeitos do estádio de maturação na colheita sobre o desenvolvimento de danos por frio em ameixas variam com o tipo de dano de frio. Segundo Crisosto et al. (2004), ameixas 'Blackamber', quando colhidas precocemente, são mais suscetíveis a dano por frio manifestado, como polpa escurecida, e, quando colhidas tardiamente, são mais suscetíveis a dano por frio manifestado, como polpa translúcida. Outros estudos, com várias cultivares de ameixas, mostram que, em frutos colhidos em estádio avançado de maturação, o dano por frio manifesta-se na forma de polpa gelatinosa (ABDI et al., 1997).

O condicionamento pré-armazenamento dos frutos, por um a dois dias a $20^{\circ} \mathrm{C}$ (pré-maturação), e o aquecimento intermitente dos frutos (por $24 \mathrm{~h}$, a $20^{\circ} \mathrm{C}$ ), a cada 10 a 14 dias, durante o armazenamento a $0^{\circ} \mathrm{C}$, são algumas das estratégias de manejo póscolheita de frutos de caroço que podem ser utilizadas para minimizar o risco de dano por frio (LURIE; CRISOSTO, 2005).

O 1-metilciclopropeno (1-MCP), um inibidor da ação do etileno, retarda a maturação pós-colheita em ameixas, na cultivar Laetitia (ARGENTA et al., 2003) e em tantas outras (DONG et al., 2002; MARTÍNEZ-ROMERO et al., 2003; MENNITI et al., 2004; KHAN; SINGH, 2007; CANDAN et al., 2008). No entanto, poucos desses estudos reportam os efeitos do 1-MCP sobre o desenvolvimento de dano por frio. O 1-MCP reduz o desenvolvimento de danos por frio em ameixas 'Fortune' (MENNITI et al., 2004) e 'Larry Ann' (CANDAN et al., 2008), embora aumente a incidência de dano por frio em pêssego (FAN et al., 2002), nectarina (DONG et al., 2001a) e damasco (DONG et al., 2002), dependendo da temperatura de armazenamento dos frutos e da época de sua aplicação.

Em ameixas 'Laetitia', o dano por frio manifesta-se através do desenvolvimento de escurecimento da polpa, quando os frutos são armazenados a $0^{\circ} \mathrm{C}$ por longos períodos, conforme relatado por empresas armazenadoras e empacotadoras do Sul do Brasil. No entanto, Argenta et al. (2003) não detectaram esse distúrbio nos frutos desta cultivar, mesmo depois de 50 dias de armazenamento refrigerado a $0^{\circ} \mathrm{C}$.

$\mathrm{O}$ presente estudo teve por objetivo avaliar os efeitos do estádio de maturação na colheita e do tratamento com 1-MCP sobre o desenvolvimento de danos por frio em ameixas 'Laetitia' cultivadas no Sul do Brasil.

\section{MATERIAL E MÉTODOS}

Ameixas cv. Laetitia (Prunus salicina) foram colhidas em pomares comerciais, nos municípios de Lages (altitude de $850 \mathrm{~m}$ ) e São Joaquim (altitude de 1200 m), no Estado de Santa Catarina, em dois estádios de maturação. No município de Lages, as ameixas foram colhidas nos dias 14 (maturação 1) e 26 (maturação 2) de janeiro, no ano de 2006, e nos dias 18 (maturação 1) e 24 (maturação 2) de janeiro, no ano de 2008. No município de São Joaquim, as ameixas foram colhidas apenas no ano de 2008, nas mesmas datas de colheita do município de Lages. As datas de colheita e os estádios de maturação nos dois municípios foram definidos levando em consideração a percentagem de cor vermelha na superfície dos frutos. Na maturação 1 (primeira colheita), selecionaram-se frutos que apresentavam superfície com $20 \%$ a $45 \%$ de cor vermelha, enquanto, na 
maturação 2 (segunda colheita), selecionaram-se frutos que apresentavam superfície com $46 \%$ a $80 \%$ de cor vermelha.

Os frutos foram armazenados em uma câmara fria sob atmosfera do ar, a $0,5^{\circ} \mathrm{C} \pm 0,5^{\circ} \mathrm{C}$ e $90-95 \%$ de umidade relativa, $36 \mathrm{~h}$ após a colheita, tratados depois de quatro dias com zero (testemunha) ou $0,5 \mu \mathrm{L} . \mathrm{L}^{-1} \mathrm{de}$ 1-MCP, e então mantidos sob refrigeração (em câmara comercial de $1.000 \mathrm{~m}^{3}$, contendo 150 toneladas de frutos) por até 73 dias. tratamento dos frutos com 1-MCP foi realizado em câmara de $1 \mathrm{~m}^{3}$, conforme metodologia descrita por Argenta et al. (2003).

A qualidade de cada fruto foi analisada na colheita e, periodicamente, durante o armazenamento refrigerado (a cada 10 dias em 2006 e a cada 6 a 10 dias em 2008), após zero ou três dias sob temperatura de $22 \pm 4^{\circ} \mathrm{C}$, simulando a vida de prateleira. Zero dia significa que os frutos foram analisados em menos de 6 horas após a retirada da câmara fria. Os frutos foram analisados a partir do $10^{\circ}(\mathrm{em} \mathrm{2006})$ ou $24^{\circ}(\mathrm{em}$ 2008) dia de armazenamento refrigerado.

A firmeza da polpa foi medida em dois lados opostos da superfície de cada fruto, na região equatorial, pela utilização de um penetrômetro eletrônico com ponteira de $8 \mathrm{~mm}$ (ARGENTA et al., 2003). Os teores de sólidos solúveis (SS) e a acidez titulável (AT) foram determinados apenas em frutos da primeira colheita, do pomar de Lages, em 2006, conforme metodologia descrita por Argenta et al. (2003). Os teores de SS e a AT foram quantificados no suco preparado com espremedor motorizado tipo centrífuga. O teor de SS foi medido usandose refratômetro digital (Atago, Tokyo), e a AT, determinada pela titulação de $10 \mathrm{~mL}$ de suco com $\mathrm{NaOH}$ a $0,1 \mathrm{~N}$ até $\mathrm{pH} 8,2$, usando-se um titulador automático (Radiometer, França).

O desenvolvimento de murcha e de podridões foi analisado atribuindo-se notas 1 pela presença ou 2 pela ausência de sintomas. O grau de severidade do escurecimento da polpa foi analisado visualmente, na secção transversal dos frutos, cortados na região equatorial, atribuindo-se notas 1 (ausência de escurecimento), 2 (menos de $30 \%$ da superfície escurecida) e 3 (mais de $30 \%$ da superfície escurecida).

A firmeza da polpa e o desenvolvimento de escurecimento da polpa foram avaliados apenas para frutos sem sintomas de murcha e podridões, respectivamente.

Os dados de cada município e ano foram analisados separadamente, utilizando-se do delineamento inteiramente casualisado, segundo esquema fatorial $2 \times 2 \times 2$ (correspondente aos dois estádios de maturação, duas doses de 1-MCP e dois períodos de vida de prateleira). Foram utilizadas
50 repetições por tratamento, cada repetição correspondendo a um fruto, para avaliar os efeitos de estádio de maturação na colheita, tratamento com 1-MCP e dias de vida de prateleira, nas análises de firmeza de polpa, escurecimento de polpa, murcha e podridões. Os efeitos destes mesmos fatores sobre os teores AT e SS foram determinados em três repetições de cinco frutos.

Os dados foram submetidos à análise de variância (ANOVA) para avaliar os efeitos de estádio de maturação na colheita, tratamento com 1-MCP e tempo de vida de prateleira $(\mathrm{p}<0,05)$, sendo as médias de período de armazenamento refrigerado de cada tratamento comparadas através de teste de Fischer $(p<0,05)$, utilizando o programa SAS. Os índices de escurecimento da polpa e podridões foram transformados $\left(y=1 / x^{2}\right)$ antes de serem submetidos a ANOVA.

\section{RESULTADOS E DISCUSSÃO}

A firmeza da polpa na colheita, em frutos do estádio de maturação 2 , foi menor em relação a frutos do estádio de maturação $1(\mathrm{p}<0,05)$, nos dois municípios e anos de execução do trabalho (Figuras 1 e 2). Esses dados confirmam que os frutos colhidos no estádio de maturação 2 , com base na análise visual subjetiva da cor vermelha, realmente estavam mais maduros do que aqueles colhidos no estádio de maturação 1 .

O tratamento com 1-MCP retardou a perda de firmeza da polpa das ameixas durante e após o armazenamento refrigerado, em ambos os municípios (Figuras 1 e 2). Em frutos da primeira colheita, no município de Lages, esse efeito do 1-MCP foi mais evidente após três dias do que após zero dia de vida de prateleira, especialmente após curto período de armazenagem a $0,5^{\circ} \mathrm{C}$ (Figura 1). Não foi identificado efeito consistente do ponto de colheita sobre a eficiência do 1-MCP para a preservação da firmeza da polpa.

O etileno endógeno produzido por ameixas regula a atividade de enzimas associadas à degradação de componentes da parede celular e à perda de firmeza da polpa (DONG et al., 2001b). Em razão disto, a menor produção de etileno, ocasionada pelo tratamento com 1-MCP, reduz a perda de firmeza de polpa após a colheita em várias cultivares de ameixas (DONG et al., 2002; MENNITI et al., 2004; KHAN; SINGH, 2007; CANDAN et al., 2008), inclusive em ameixas 'Laetitia' (ARGENTA et al., 2003) (Figuras 1 e 2). A redução na perda de firmeza após o tratamento com 1-MCP tem sido 
observada mesmo em cultivares de ameixas que não apresentam padrão climatérico típico (MARTÍNEZ-ROMERO et al., 2003).

No município de Lages, em 2006, a redução nas perdas de AT e SS com a aplicação de 1-MCP não foi consistente, ao longo do período de armazenagem, em avaliações feitas na retirada da câmara fria e após vida de prateleira (Figura 3). Esses resultados confirmam dados de outros autores, mostrando que o 1-MCP não apresenta efeito na preservação pós-colheita dos valores de AT e SS em ameixas (DONG et al., 2001b; MENNITI et al., 2004). Alguns trabalhos mostram que o tratamento 1-MCP pode diminuir a relação SS/AT durante o armazenamento refrigerado, através da redução na perda de AT, porém sem afetar o teor de SS (DONG et al., 2002; ARGENTA et al., 2003; MARTÍNEZROMERO et al., 2003).

Ameixas 'Laetitia' desenvolveram escurecimendo de tecidos da polpa mais severo próximo ao caroço, semelhante ao sintoma de dano por frio descrito por Crisosto et al. (2004). Sintomas de dano por frio em frutos de caroço (Prunus spp.) variam em função da espécie e cultivar, e são identificados pela perda da capacidade de amadurecer após a refrigeração e por alterações indesejáveis da textura (polpa endurecida, 'lanosa', farinácea ou gelatinosa, com perda da suculência) e da aparência (polpa escurecida, avermelhada ou translúcida, e descoloração irregular da região vermelha da epiderme) (MITCHELL; KADER, 1989; LURIE; CRISOSTO, 2005).

O sintoma de escurecimento da polpa, observado no presente estudo, aumentou com o tempo de armazenamento refrigerado e foi reduzido pelo tratamento 1-MCP, independentemente do município e ano (Tabelas 1 e 2). Esse distúrbio desenvolveu-se enquanto os frutos estavam na câmara fria (zero dia de prateleira), embora a severidade dos sintomas tenha aumentado após três dias de vida de prateleira. $\mathrm{O}$ escurecimento da polpa foi mais severo e ocorreu mais cedo, a partir do início do armazenamento refrigerado, nos frutos colhidos no estádio de maturação 1 (mais firmes e menos avermelhados) do que naqueles colhidos no estádio de maturação 2 (menos firmes e mais avermelhados), especialmente quando não tratados com 1-MCP, nos dois municípios e anos. Adicionalmente, a ocorrência de escurecimento de polpa, em 2008, foi maior em frutos colhidos em São Joaquim do que em Lages, dependendo dos períodos de armazenagem e de vida de prateleira, e do tratamento com ou sem 1-MCP (Tabela 2). Essa diferença de suscetibilidade entre os locais de produção ao dano por frio pode estar relacionada, em parte, à maior firmeza da polpa na colheita, dos frutos oriundos de São Joaquim (frutos imaturos na colheita) em relação aos frutos provenientes de Lages. A ausência de dano por frio em ameixas 'Laetitia', armazenadas por 50 dias a $0^{\circ} \mathrm{C}$, reportada por Argenta et al. (2003), pode estar relacionada ao estádio avançado de maturação na colheita, dos frutos usados por estes autores.

O desenvolvimento de escurecimento da polpa em frutos de caroço pode resultar de comprometimento da permeabilidade seletiva das membranas, levando a interação entre fenóis e oxidases de fenóis (os quais, em geral, estão separados em diferentes compartimentos celulares), associado à senescência de tecidos (LURIE; CRISOSTO, 2005). Essa hipótese é sustentada pelo fato de o 1-MCP, um inibidor da ação do etileno, retardar a maturação e a senescência de frutos, reduzindo assim o desenvolvimento de escurecimento de polpa em ameixas (Tabelas 1 e 2) (MENNITI et al., 2004; CANDAN et al., 2008). Entretanto, a relação entre a ação do etileno, senescência e desenvolvimento de escurecimento da polpa em frutos de caroço, após a armazenagem refrigerada, ainda não está claramente definida, considerando que esse distúrbio é mais severo quando ameixas são colhidas precocemente (Tabelas 1 e 2) e quando pêssegos e nectarinas são tratados com 1-MCP (FAN et al., 2002; DONG et al., 2001a).

É interessante observar que a perda de firmeza durante os três dias de vida de prateleira foi maior após curtos períodos de armazenagem refrigerada, independentemente do município e do ano de produção (Figuras 1 e 2). Argenta et al. (2003) reportaram redução na produção de etileno em ameixas 'Laetitia', quantificada após a remoção da armazenagem refrigerada, quando os frutos permaneceram durante cinco dias a $23^{\circ} \mathrm{C}$, com o prolongamento no período de armazenamento a $0^{\circ} \mathrm{C}$, de 20 para 50 dias. Portanto, a menor perda de firmeza de polpa durante o período de vida de prateleira, com o prolongamento no período de armazenamento refrigerado (Figuras 1 e 2), pode ser consequência da menor capacidade de produção de etileno dos frutos. Frutos com sintomas de murcha não foram avaliados quanto à firmeza da polpa no presente estudo. Por isso, a menor perda de firmeza de polpa após longos períodos de armazenagem refrigerada pode também ser uma forma de expressão de dano por frio. Mais estudos serão necessários para confirmar essa suposição, através da análise aprofundada de outros atributos da textura, bem como de suculência.

O potencial de armazenagem de pêssegos, nectarinas e ameixas normalmente é limitado, prin- 
cipalmente em razão da perda de firmeza de polpa, do desenvolvimento de danos por frio e da ocorrência de podridões. A incidência de podridões e murcha não limitou o potencial de armazenagem de ameixas 'Laetitia', pois foram sempre inferiores a $0,5 \%$ e $1 \%$, respectivamente, mesmo depois de longos períodos de armazenagem, independentemente do município e do ano (dados não apresentados). $\mathrm{O}$ tratamento 1-MCP não afetou significativamente a incidência de podridões e murcha (dados não apresentados).

A baixa firmeza da polpa pode limitar o manuseio e o transporte após a colheita de frutos de caroço, tornado-os altamente sensíveis a danos mecânicos. Além disso, consumidores podem rejeitar frutos de caroço com baixa firmeza de polpa $(<2 \mathrm{lb})$ (CRISOSTO, 1999). Nesse sentido, os resultados do presente estudo indicam que ameixas 'Laetitia' podem ser armazenadas por até 73 dias a $0,5^{\circ} \mathrm{C}$, tomando como referencial apenas a firmeza de polpa, considerando que até esse período os frutos mantiveram firmeza da polpa $>2 \mathrm{lb}$, independentemente do município, estádio de maturação na colheita e tratamento com 1-MCP (Figuras 1 e 2). No entanto, o potencial de armazenagem das ameixas 'Laetitia' foi limitado pelo desenvolvimento de escurecimento de polpa.

Houve efeito aditivo da colheita dos frutos em estádio mais avançado de maturação e do tratamento com 1-MCP sobre o retardamento do aparecimento de escurecimento da polpa durante o armazenamento refrigerado, avaliado após três dias de vida de prateleira. No município de São Joaquim, em 2008, frutos que não reberam tratamento com 1-MCP, apresentaram escurecimento de polpa a partir do $31^{\circ}$ e $45^{\circ}$ dia de armazenamento refrigerado, quando colhidos nos estádios de maturação 1 e 2 , respectivamente; ao serem tratados com 1-MCP, apresentaram o distúrbio a partir do $38^{\circ}$ e $52^{\circ}$ dias de armazenamento, quando colhidos nos estádios de maturação 1 e 2 , respectivamente (Tabela 2). No município de Lages, frutos colhidos no estádio de maturação 1 , que não receberam tratamento com 1-MCP, apresentaram o distúrbio a partir do $40^{\circ} \mathrm{e}$ $45^{\circ}$ dias de armazenamento refrigerado, nos anos de 2006 e 2008, respectivamente; ao serem tratados com 1-MCP, apresentaram o distúrbio a partir do $50^{\circ}$ e $66^{\circ}$ dias de armazenamento, nos anos de 2006 e 2008, respectivamente (Tabelas 1 e 2). Neste mesmo município, frutos colhidos no estádio de maturação 2, e que não receberam tratamento com 1-MCP, apresentaram o distúrbio a partir do $50^{\circ} \mathrm{e}$ $59^{\circ}$ dias de armazenamento refrigerado, nos anos de 2006 e 2008, respectivamente; ao serem tratados com 1-MCP, apresentaram o distúrbio a partir do $60^{\circ}$ dia de armazenamento, no ano de 2006, e não manifestram o distúrbio, mesmo aos 66 dias de armazenamento, no ano de 2008 (Tabelas 1 e 2).

Portanto, a associação de colheita de frutos no estádio de maturação 2 e tratamento com um 1-MCP aumentou em mais de 20 dias o período de armazenamento refrigerado sem ocorrência de escurecimento de polpa, avaliada após três dias de vida de prateleira, em relação a frutos colhidos no estádio de maturação 1 e não tratados com 1-MCP, independentemente do município.

Este trabalho demonstra como o ponto de colheita e o tratamento com 1-MCP podem retardar a manifestação e a severidade do escurecimento da polpa, bem como preservar a firmeza de polpa de ameixas 'Laetitia' durante o armazenamento refrigerado. Considerando que em uma mesma câmara de armazenagem comercial frequentemente são armazenadas ameixas de diferentes locais e/ou datas de colheita, esses resultados evidenciam a importância do monitoramento semanal da qualidade dos frutos para cada lote, como forma de escalonar a comercialização, de acordo com seu potencial de armazenagem. 
TABELA 1 - Índice de escurecimento da polpa em ameixa 'Laetitia', durante o armazenamento refrigerado a $0,5^{\circ} \mathrm{C}$, após zero ou três dias (d) de amadurecimento a $22^{\circ} \mathrm{C}$. Os dados referem-se a frutos colhidos no município de Lages, no ano de 2006, nos estádios de maturação 1 (primeira colheita) e 2 (segunda colheita), sem (Test; testemunha) ou com aplicação de 1-MCP.

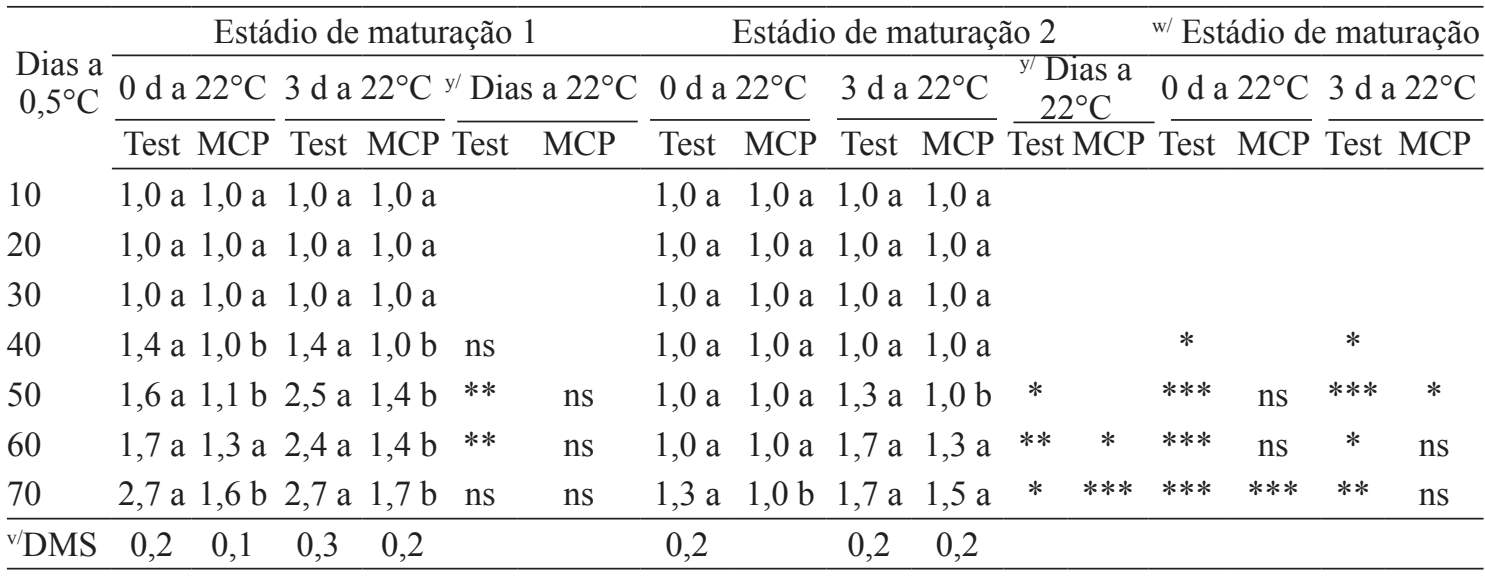

Médias seguidas de letra diferente, na linha (comparando frutos não tratados e frutos tratados com 1-MCP), para uma mesma combinação de estádio de maturação e período a $22^{\circ} \mathrm{C}$, diferem significativamente $(\mathrm{p}<0,05)$.

Médias não seguidas por letras apresentaram variância nula.

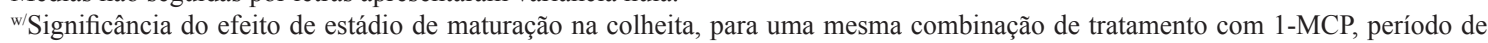
armazenamento a $0,5^{\circ} \mathrm{C}$ e período a $22^{\circ} \mathrm{C}$ : $\mathrm{ns},{ }^{*},{ }^{*}, * * *$ : não significativo, $\mathrm{p}<0,05, \mathrm{p}<0,01$, e $\mathrm{p}<0,001$, respectivamente.

${ }^{\mathrm{y}}$ Significância do efeito do período a $22^{\circ} \mathrm{C}$ (maturação pós-armazenagem), para uma mesma combinação de tratamento com 1-MCP e período de armazenamento a $0,5^{\circ} \mathrm{C}: \mathrm{ns},{ }^{*}, * *, * * *$ : não significativo, $\mathrm{p}<0,05, \mathrm{p}<0,01$, e $\mathrm{p}<0,001$, respectivamente.

${ }^{\mathrm{v} /}$ Diferença mínima significativa (DMS), determinada pelo teste de Fisher $(\mathrm{p}<0,05)$, para o efeito de período de armazenamento a $0,5^{\circ} \mathrm{C}$ (para dados apresentados em uma mesma coluna).

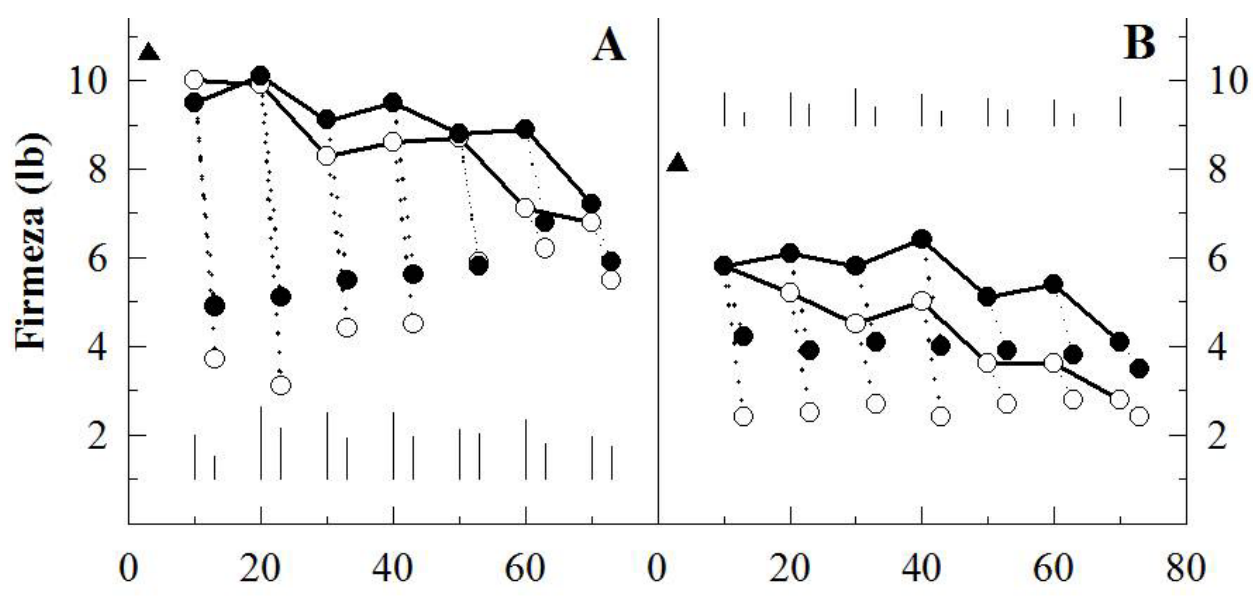

\section{Dias de armazenagem}

FIGURA 1 - Firmeza da polpa em ameixas 'Laetitia', colhidas no município de Lages- SC, no ano de 2006, nos estádios de maturação $1(\mathbf{A})$ e $2(\mathbf{B})$, avaliada na colheita $(\boldsymbol{\Delta})$ e após o armazenamento refrigerado mais zero $(\circ, \bullet)$ e três $(\mathbf{\square}, \square)$ dias de vida de prateleira a $22^{\circ} \mathrm{C}$. Os frutos foram tratados com $0(\circ, \square)$ ou $0,5 \mu \mathrm{L} \mathrm{L}^{-1}(\bullet, \mathbf{\square})$ de $1-\mathrm{MCP}$, a $0,5^{\circ} \mathrm{C}$, quatro dias após a colheita, e então armazenados sob atmosfera do ar a $0,5^{\circ} \mathrm{C} \pm 0,5^{\circ} \mathrm{C}$. Os símbolos sobre as linhas contínuas referem-se à firmeza de polpa no dia zero (na retirada da câmara refrigerada), enquanto os símbolos sobre linhas pontilhadas se referem à firmeza de polpa após três dias da retirada da câmara fria (vida de prateleira a $22^{\circ} \mathrm{C}$ ). A altura de cada barra vertical no interior de cada gráfico representa o valor da diferença mínima significativa $(\mathrm{p}<0,05)$ para efeito de tratamento com 1-MCP, para cada período de armazenagem e de vida de prateleira. 
TABELA 2 - Índice de escurecimento da polpa em ameixa 'Laetitia', durante a armazenagem refrigerada a $0,5^{\circ} \mathrm{C}$, após zero ou três dias (d) de amadurecimento a $22^{\circ} \mathrm{C}$. Os dados se referem a frutos colhidos nos município de São Joaquim e Lages, no ano de 2008, nos estádios de maturação 1 (primeira colheita) e 2 (segunda colheita), sem (Test; testemunha) ou com aplicação de 1-MCP.

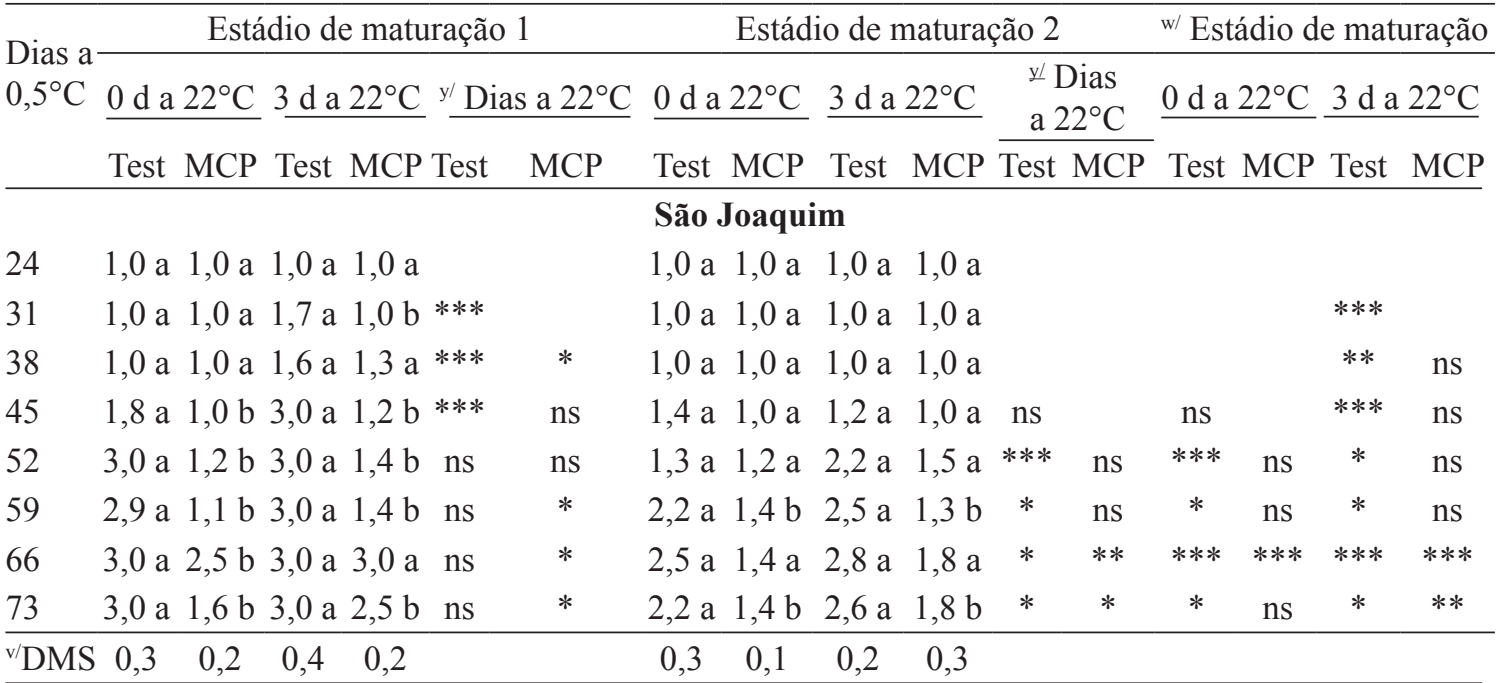

\section{Lages}

$24 \quad 1,0$ a 1,0 a 1,0 a 1,0 a

1,0 a 1,0 a 1,0 a 1,0 a

311,0 a 1,0 a 1,0 a 1,0 a

1,0 a 1,0 a 1,0 a 1,0 a

$38 \quad 1,0$ a 1,0 a 1,0 a 1,0 a

1,0 a 1,0 a 1,0 a 1,0 a

$45 \quad 1,3$ a 1,0 b 1,8 a 1,0 b *

521,8 a 1,0 b 2,6 a 1,0 b *

$59 \quad 1,9$ a 1,0 b 2,9 a 1,0 b **

$66 \quad 2,8$ a 1,0 b 3,0 a 1,7 b Ns

$73 \quad 2,9$ a 1,3 b 3,0 a 3,0 a ns

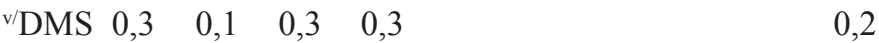

Médias seguidas de letra diferente, na linha (comparando frutos não tratados e frutos tratados com 1-MCP), para uma mesma combinação de estádio de maturação e período a $22^{\circ} \mathrm{C}$, diferem significativamente $(\mathrm{p}<0,05)$.

Médias não seguidas por letras apresentaram variância nula.

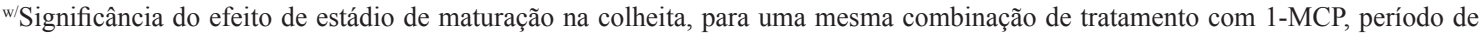
armazenamento a $0,5^{\circ} \mathrm{C}$ e período a $22^{\circ} \mathrm{C}$ : ns, ${ }^{*}, * *, * * *$ : não significativo, $\mathrm{p}<0,05, \mathrm{p}<0,01$, e $\mathrm{p}<0,001$, respectivamente.

${ }^{\mathrm{y}}$ Significância do efeito do período a $22^{\circ} \mathrm{C}$ (maturação pós-armazenagem), para uma mesma combinação de tratamento com 1-MCP e período de armazenamento a $0,5^{\circ} \mathrm{C}$ : ns, ${ }^{*}, * *, * * *$ : não significativo, $\mathrm{p}<0,05, \mathrm{p}<0,01$, e $\mathrm{p}<0,001$, respectivamente.

${ }^{v} /$ Diferença mínima significativa (DMS), determinada pelo teste de Fisher $(\mathrm{p}<0,05)$, para o efeito de período de armazenamento a $0,5^{\circ} \mathrm{C}$ (para dados apresentados em uma mesma coluna). 


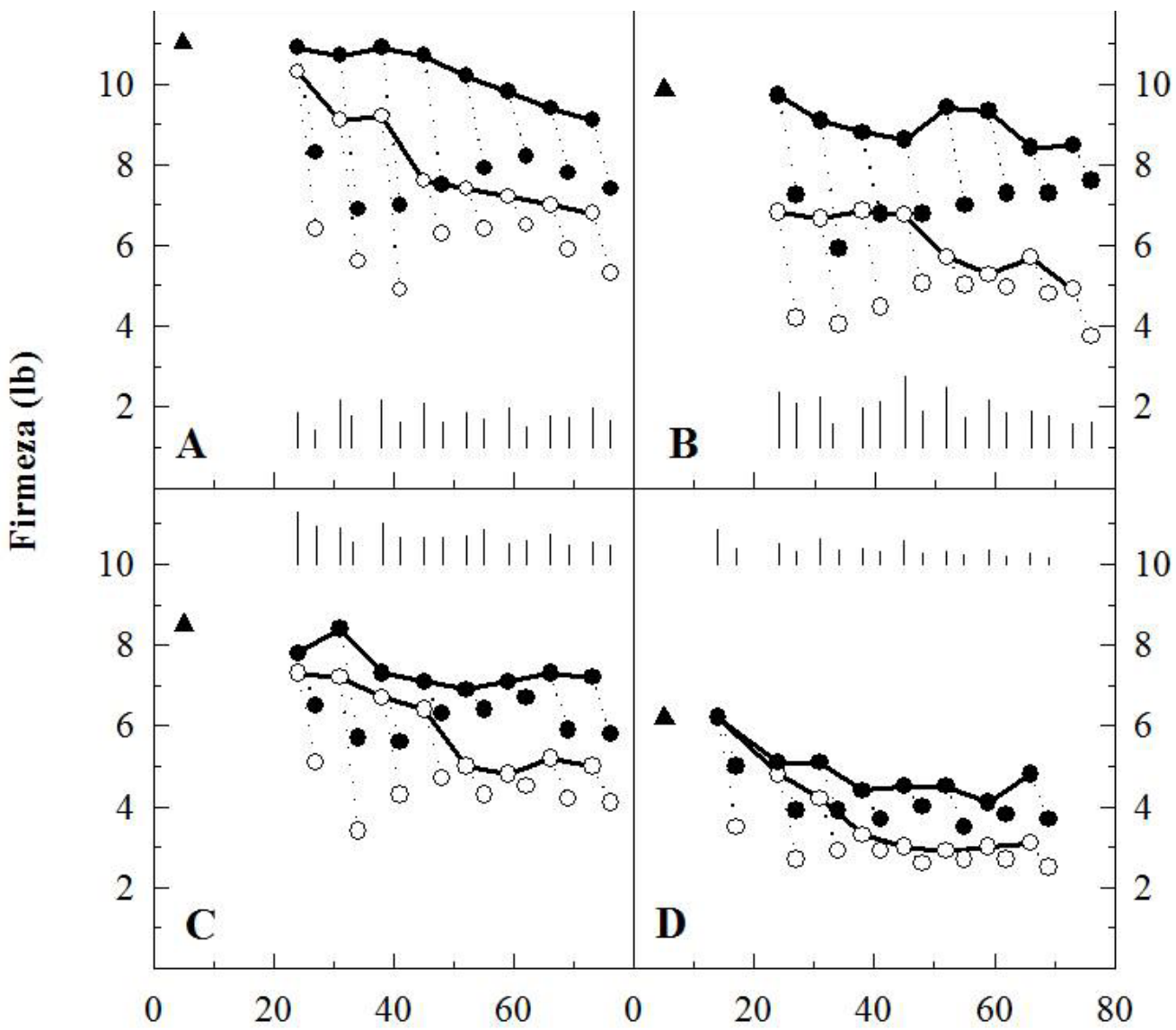

Dias de armazenagem

FIGURA 2 - Firmeza da polpa em ameixas 'Laetitia', colhidas nos municípios de São Joaquim (A e B) e Lages (C e D), SC, no ano de 2008, nos estádios de maturação 1 (A e C) e 2 (B e D), avaliada na colheita $(\boldsymbol{\Lambda})$ e após o armazenamento refrigerado mais zero $(\circ, \bullet)$ e três $(\boldsymbol{\bullet}, \square)$ dias de vida de prateleira a $22^{\circ} \mathrm{C}$. Os frutos foram tratados com $0(\circ, \square)$ ou $0,5 \mu \mathrm{L} \mathrm{L}^{-1}(\bullet, \mathbf{\square})$ de $1-\mathrm{MCP}$, a $0,5^{\circ} \mathrm{C}$, quatro dias após a colheita, e então armazenados sob atmosfera do ar a $0,5^{\circ} \mathrm{C} \pm 0,5^{\circ} \mathrm{C}$. Os símbolos sobre as linhas contínuas referem-se à firmeza de polpa no dia zero (na retirada da câmara refrigerada), enquanto os símbolos sobre linhas pontilhadas se referem à firmeza de polpa após três dias da retirada da câmara fria (vida de prateleira a $22^{\circ} \mathrm{C}$ ). A altura de cada barra vertical no interior de cada gráfico representa o valor da diferença mínima significativa $(\mathrm{p}<0,05)$ para efeito de tratamento com 1-MCP, para cada período de armazenagem e de vida de prateleira. 


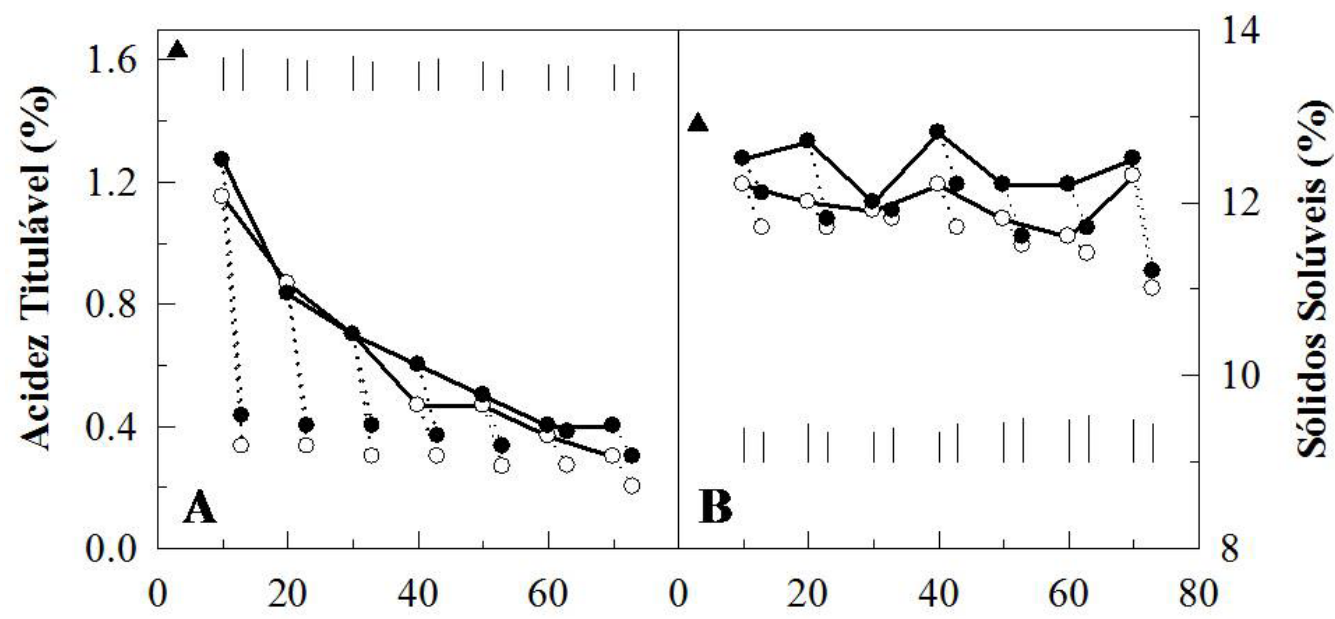

\section{Dias de armazenagem}

FIGURA 3 - Acidez titulável (A) e teor de sólidos solúveis (B) em ameixas 'Laetitia', colhidas no município de Lages- SC, no ano de 2006, no estádio de maturação 1 (primeira data de colheita), avaliada na colheita $(\boldsymbol{\Lambda})$ e após o armazenamento refrigerado mais zero $(\circ, \bullet)$ e três $(\boldsymbol{\bullet}, \square)$ dias de vida de prateleira a $22^{\circ} \mathrm{C}$. Os frutos foram tratados com $0(\circ, \square)$ ou $0,5 \mu \mathrm{L} \mathrm{L}^{-1}(\bullet, \mathbf{\square})$ de $1-\mathrm{MCP}$, a $0,5^{\circ} \mathrm{C}$, quatro dias após a colheita, e então armazenados sob atmosfera do ar a $0,5^{\circ} \mathrm{C} \pm 0,5^{\circ} \mathrm{C}$. Os símbolos sobre as linhas contínuas referem-se a valores de acidez titulável e teor de sólidos solúveis no dia zero (na retirada da câmara refrigerada), enquanto os símbolos sobre linhas pontilhadas se referem a valores após três dias da retirada da câmara refrigerada (vida de prateleira a $22^{\circ} \mathrm{C}$ ). A altura de cada barra vertical no interior de cada gráfico representa $\mathrm{o}$ valor da diferença mínima significativa $(\mathrm{p}<0,05)$ para efeito de tratamento com $1-\mathrm{MCP}$, para cada período de armazenagem e de vida de prateleira.

\section{CONCLUSÕES}

1- Ameixas 'Laetitia' colhidas precocemente são mais suscetíveis ao desenvolvimento de dano por frio que aquelas colhidas tardiamente.

2- O tratamento com 1-MCP retarda o desenvolvimento pós-colheita do dano por frio e a perda da firmeza de polpa de ameixas 'Laetitia'.

3- A colheita de ameixas 'Laetitia' em estádio avançado de maturação (correspondente a $46 \%$ e $80 \%$ de superfície vermelha) e o tratamento com 1-MCP retardam o início dos sintomas de dano por frio durante o armazenamento refrigerado.

\section{AGRADECIMENTOS}

À AgroFresh Inc., pelo fornecimento do 1-MCP (SmartFresh $\left.{ }^{\mathrm{SM}}\right)$.

\section{REFERÊNCIAS}

ABDI, N.; HOLFORD, P.; McGLASSON, W.B. Effects of harvest maturity on storage life of Japanese type plums. Australian Journal of Experimental Agriculture, Collingwood, v.37, n.3, p.391-397, 1997.

ARGENTA, L.C.; KRAMMES, J.G.; MEGGUER, C.A.; AMARANTE, C.V.T.; MATTHEIS, J. Ripening and quality of 'Laetitia' plums following harvest and cold storage as affected by inhibition of ethylene action. Pesquisa Agropecuária Brasileira, Brasília, v.38, n.10, p.1139-1148, 2003.

CANDAN, A.P.; GRAELL, J.; LARRIGAUDIÈRE, C. Roles of climacteric ethylene in the development of chilling injury in plums. Postharvest Biology and Technology, Amsterdam, v.47, n.1, p.107-112, 2008.

CRISOSTO, C.H. Optimum procedures for ripening stone fruit. In: UNIVERSITY OF CALIFORNIA (Ed.). Management of fruit ripening. Davis, 1999, p.28-30. (Postharvest Horticulture Series,.9). 
CRISOSTO, C.H.; MITCHELL, F.G.; JU, Z. Susceptibility to chilling injury of peach, nectarine, and plum cultivars grown in California. HortScience, Alexandria, v.34, n.6, p.1116-1118, 1999.

CRISOSTO, C.H.; GARNER, D.; CRISOSTO, G.M.; BOWERMAN, E. Increasing 'Blackamber' plum (Prunus salicina Lindell) consumer acceptance. Postharvest Biology and Technology, Amsterdam, v.34, n.3, p.237-244, 2004.

DONG, L.; ZHOU, H.-W.; SONEGO, L.; LERS, A.; LURIE, S. Ethylene involvement in the cold storage disorder of 'Flavortop' nectarine. Postharvest Biology and Technology, Amsterdam, v.23, n.2, p.105-115, 2001a.

DONG, L.; ZHOU, H.-W.; SONEGO, L.; LERS, A.; LURIE, S. Ripening of 'Red Rosa' plums: effect of ethylene and 1-methylcyclopropene. Australian Journal of Plant Physiology, Collingwood, v.28, n.10, p.1039-1045, $2001 \mathrm{~b}$.

DONG, L.; LURIE, S.; ZHOU, H-W. Effect of 1-methylcyclopropene on ripening of 'Canino' apricots and 'Royal Zee' plums. Postharvest Biology and Technology, Amsterdam, v.24, n.2, p.135-145, 2002.

DUCROQUET, J.-P.H.J.; ANDRADE, E.R.; HICKEL, E.R. A escaldadura das folhas da ameixeira em Santa Catarina. Florianópolis: EPAGRI, 2001. 55p. (Boletim Técnico, 118).

FAN, X.; ARGENTA, L.C.; MATTHEIS, J.P. Interactive effects of 1-MCP and temperature on 'Elberta' peach quality. Hortcience, Alexandria, v.37, n.1, p.134-138, 2002.
KADER, A.A.; MITCHELL, F.G. Postharvest physiology. In: LARUE, J.H.; JOHNSON, R.S. (Ed.). Peaches, plums and nectarines: growing and handling for fresh market. Davis: University of California, 1989. p.158-164.

KHAN, A.S.; SINGH, Z. 1-MCP regulates ethylene biosynthesis and fruit softening during ripening of 'Tegan Blue' plum. Postharvest Biology and Technology, Amsterdam, v.43, n.3, p.298-306, 2007.

LURIE, S.; CRISOSTO, C.H. Chilling injury in peach and nectarine. Postharvest Biology and Technology, Amsterdam, v.37, n.3, p.195-208, 2005.

MARTÍNEZ-ROMERO, D.; DUPILLE, E.; GUILLÉN, F.; VALVERDE, J.M.; SERRANO, M.; VALERO, D.J. 1-methylcyclopropene increases storability and shelf life in climacteric and non climacteric plums. Journal of Agricultural and Food Chemistry, Washington, v.51, n.16, p.4680-4686, 2003.

MENNITI, A.M.; GREGORI, R.; DONATI, I. 1-Methylcyclopropene retards postharvest softening of plums. Postharvest Biology and Technology, Amsterdam, v.31, n.3, p.269-275, 2004.

MITCHELL, F.G.; KADER, A.A. Factors affecting deterioration rate. In: LARUE, J.H.; JOHNSON, R.S. (Eds.) Peaches, plums and nectarines: growing and handling for fresh market. Davis: University of California, 1989. p.165-178. 